\title{
Integration of Multifidelity Multidisciplinary Computer Codes for Design and Analysis of Supersonic Aircraft
}

\author{
Karl A. Geiselhart ${ }^{1}$ and Lori P. Ozoroski ${ }^{2}$ \\ NASA Langley Research Center, Hampton, Virginia 23681, USA \\ James W. Fenbert ${ }^{3}$ and Elwood W. Shields ${ }^{4}$ \\ Alliant Techsystems, Inc., Hampton, Virginia 23681, USA \\ and \\ $\mathrm{Wu} \mathrm{Li}{ }^{5}$ \\ NASA Langley Research Center, Hampton, Virginia 23681, USA
}

This paper documents the development of a conceptual level integrated process for design and analysis of efficient and environmentally acceptable supersonic aircraft. To overcome the technical challenges to achieve this goal, a conceptual design capability which provides users with the ability to examine the integrated solution between all disciplines and facilitates the application of multidiscipline design, analysis, and optimization on a scale greater than previously achieved, is needed. The described capability is both an interactive design environment as well as a high powered optimization system with a unique blend of low, mixed and high-fidelity engineering tools combined together in the software integration framework, ModelCenter. The various modules are described and capabilities of the system are demonstrated. The current limitations and proposed future enhancements are also discussed.

\footnotetext{
${ }^{1}$ Aerospace Engineer, Aeronautics Systems Analysis Branch, Mail Stop 442.

${ }^{2}$ Aerospace Engineer, Aeronautics Systems Analysis Branch, Mail Stop 442.

${ }^{3}$ Senior System Engineer, Aeronautics Systems Analysis Branch, Space Division.

${ }^{4}$ Senior System Engineer, Aeronautics Systems Analysis Branch, Space Division.

${ }^{5}$ Senior Research Engineer, Aeronautics Systems Analysis Branch, Mail Stop 442.
} 


\section{Nomenclature}

$\begin{array}{ll}A_{e} & =\text { equivalent area } \\ \mathrm{C}_{\mathrm{L}} & =\text { lift coefficient } \\ d p / p & =\text { (the calculated pressure }- \text { the ambient pressure)/(the ambient pressure) } \\ \mathrm{EXTR} & =\text { extraction ratio } \\ \mathrm{FPR} & =\text { fan pressure ratio } \\ \mathrm{L} / \mathrm{D} & =\text { lift to drag ratio } \\ \mathrm{nmi} & =\text { nautical miles } \\ \mathrm{OPR} & =\text { overall pressure ratio } \\ \mathrm{OML} & =\text { outer mold line } \\ \mathrm{SFC} & =\text { specific fuel consumption } \\ \mathrm{T}_{3} & =\text { compressor exit temperature, }{ }^{\circ} \mathrm{R} \\ \mathrm{T}_{4} & =\text { combustor exit temperature, }{ }^{\circ} \mathrm{R} \\ \mathrm{TTR} & =\text { throttle ratio } \\ \mathrm{V}_{\text {app }} & =\text { approach velocity, kts } \\ \mathrm{V}_{\text {jet }} & =\text { jet velocity, ft/s }\end{array}$

\section{Introduction}

$\mathrm{T}$ HE design of an efficient, environmentally acceptable, and economically viable supersonic transport remains one of the most challenging problems for aircraft designers. The solution to this design problem does not reside within one discipline but will only be found by investigating the complex interactions between various disciplines. The ability to apply integrated design in the conceptual stage is the only way to ensure that these, often conflicting areas, can effectively be explored to achieve the demanding design goals.

There are many examples of Multi Disciplinary Optimization (MDO) applications to supersonic aircraft throughout the literature. ${ }^{1-13}$ There are also many examples of conceptual aircraft design reports where the authors described going "deep" in a particular discipline, focusing on a single cruise point low-boom and/or low-drag design in their process. ${ }^{14-30}$ Many of these are often byproducts of tool and method development and the testing of optimization algorithms and/or schemes. There are fewer instances focused on supersonic design for low-boom concepts with shape optimization tied to overall vehicle performance. ${ }^{1,2,4}$ This current effort considers the lessons of the past and the need for a multi-user, robust, flexible, workhorse system capable of integrating more disciplines at multiple levels of fidelity. The present capability includes a comprehensive suite of functional modules ranging from setting up user displays and directories, selecting levels of desired analysis for different types of problems, selecting a wide range of automated plots to view during execution, to detailed inputs controlling the actual analysis codes and design optimization algorithms.

The development of an effective integrated process for multifidelity, multidisciplinary, design optimization and analysis for a low-boom and low-drag supersonic aircraft concept has been completed. This integrated process includes propulsion system design and analysis, mission performance and takeoff analyses, and community noise assessment. The process also includes low-fidelity codes for aerodynamic performance that can be used for cruise point performance and equivalent-area based sonic boom analyses. The same low-fidelity codes can also be used to generate low speed polars for takeoff and landing analyses and for generating polars for a full mission performance analysis. In addition to the low-fidelity analysis codes, there is a mixed-fidelity method for low-boom equivalentarea $\left(\mathrm{A}_{\mathrm{e}}\right)$ based design using computational fluid dynamics (CFD) codes, and a high-fidelity sonic boom analysis using off-body CFD pressure distributions for boom propagation. For $\mathrm{A}_{\mathrm{e}}$ based low-boom design, a low-boom target $A_{e}$ is needed. The integrated process includes several options for $A_{e}$ target generation: 1) it can be generated by the classic Seebass-George-Darden boom minimization theory, 2) it can be created interactively by manually adjusting an f-function or the actual $A_{e}$ distribution for a favorable ground signature and loudness, or 3 ) developed through the use of genetic optimization to minimize loudness for a numerically optimal low-boom target. The integrated process allows easy formulations of optimization of the overall aircraft at the systems level and for the evaluation of various optimization strategies.

The overall implementation details of the integrated process using ModelCenter ${ }^{\circledR} 9.0^{31}$ are given in Section II, followed by sections describing the details of various disciplinary analysis assemblies. Example capabilities of the process are demonstrated followed by conclusions and future plans. 


\section{Implementation in ModelCenter}

The analysis and design environment has been built in ModelCenter 9.0 taking full advantage of the new process flow capabilities included within the latest ModelCenter release. Figure 1 shows the high level model that has been developed for supersonic applications. The implemented process flow model is quite different from the data flow model previously developed for this application as documented in Ref. 32. One significant advantage of the process flow modeling option is that it allows independent components to execute in parallel. In addition, the implementation of logic nodes provides the ability to make seamless changes in the analysis path of the integrated process, through either user selection or analytic determination. Process flow also allows conditional links that are especially useful when integrating multifidelity analysis codes. For example, total equivalent area can be generated by high-fidelity or low-fidelity methods, and the solutions from both methods can be linked to the same downstream analysis component. One can get either a low-fidelity or high-fidelity analysis result by simply selecting the desired path. The adoption of the process flow capabilities within ModelCenter has been instrumental in developing the flexible and multifidelity capabilities presented herein. The current model also implements data objects to make large amounts of data available to multiple components in the model, greatly reducing the number of required data links in the model. In the current process, data objects are simply file variables, containing geometric, aerodynamic, configuration, and flight condition data. This development has also greatly improved model organization and maintenance over the prior capability documented in Ref. 32 .

In the early stages of low-boom and/or low-drag design, full mission performance and community noise constraints may not be as important as low-boom and low-drag design goals. Moreover, the cost of these analyses can be prohibitive even when conducting low-fidelity optimization. Therefore, a tiered approach is used for running low-fidelity analyses and using low and mixed-fidelity analyses for design optimization. In the first tier, enough data for a single cruise point analysis are generated. A lowfidelity weights analysis is included in the first tier so that Breguet range analysis results can be used as part of the objective or constraint. In the second tier, the data needed for a detailed takeoff and landing analysis are added. In the third tier, the data required to fly a full mission are added. All aerodynamic data needed for low and mixed-fidelity lowboom design are generated in all three tiers. This tiered approach allows the user to perform optimization or parametric analyses at varying levels of cost per function evaluation by switching an analysis option. A low-boom and/or low-drag optimization could be performed for cruise only, with no constraints on takeoff or landing field lengths, or at cruise combined with low speed aerodynamics to allow constraints on takeoff and landing field lengths, approach velocity, etc. at a slightly higher cost. The requirement for a full set of aerodynamic data for a complete mission performance analysis will significantly add to the overall cost and community noise computations are even more costly.

\section{Propulsion System Analysis Assembly}

Propulsion system analyses are performed using the Numerical Propulsion Simulation System $^{33}$ (NPSS) and an improved version of the Weight Analysis of Turbine Engines ${ }^{34}$ (WATE) computer code (WATE++) is used for the propulsion system weight and flow path. NPSS and WATE++ are used to generate the propulsion system weight, nacelle geometry, performance data for mission and noise analyses, and the input for low-fidelity plume shape and for CFD based engine simulation. Following the tiered approach philosophy, NPSS and WATE++ generate weights and data for the tier I cruise point analyses. NPSS and WATE++ will generate the engine state tables and geometric data for the Aircraft Noise Prediction Program ${ }^{35}$ (ANOPP) used for community noise analysis. Additionally, the model can be run with or without NPSS analysis. If the model is set to skip NPSS analysis, the existing propulsion system weight and nacelle geometry are scaled by thrust for wave drag, skin friction, CFD, and overall aircraft performance and noise analyses. There is a component in the propulsion assembly that generates the input to Vehicle Sketch Pad ${ }^{36}$ (VSP) for the nacelle geometry. The current system uses a minimum size nacelle based on 
various engine flowpath parameters from WATE++. Future improvements in this system will include new inlet, nacelle and nozzle design modules currently being developed at NASA. Integration of full NPSS models within this system is a major step forward in propulsion-airframe integration at the system design level for supersonics where traditionally these propulsion design parameters have been uncoupled from the rest of the airframe.

\section{Geometry Assembly}

In the initial stage of conceptual design, VSP is used to model the geometry. VSP is an easy-to-use parametric geometry modeler developed at NASA in recent years. A point definition of the VSP geometry, similar to PLOT3D' ${ }^{37}$ format for representing rectangular grids, is used as the standard geometry format for all analysis codes. Due to differences in geometry requirements for various codes, a geometry format conversion code hrm2geo has been developed to convert VSP geometry for both low-fidelity and high-fidelity analyses. In particular, input files for the wave drag code, the equivalent area calculation code, skin-friction drag code, linear aero codes, Cart3D ${ }^{38}$, and VGRID ${ }^{39}$ (a CFD volume meshing code) can all be generated from VSP geometry using hrm2geo. This allows both low and high-fidelity codes to use the same underlying geometry model for all analyses. VSP can

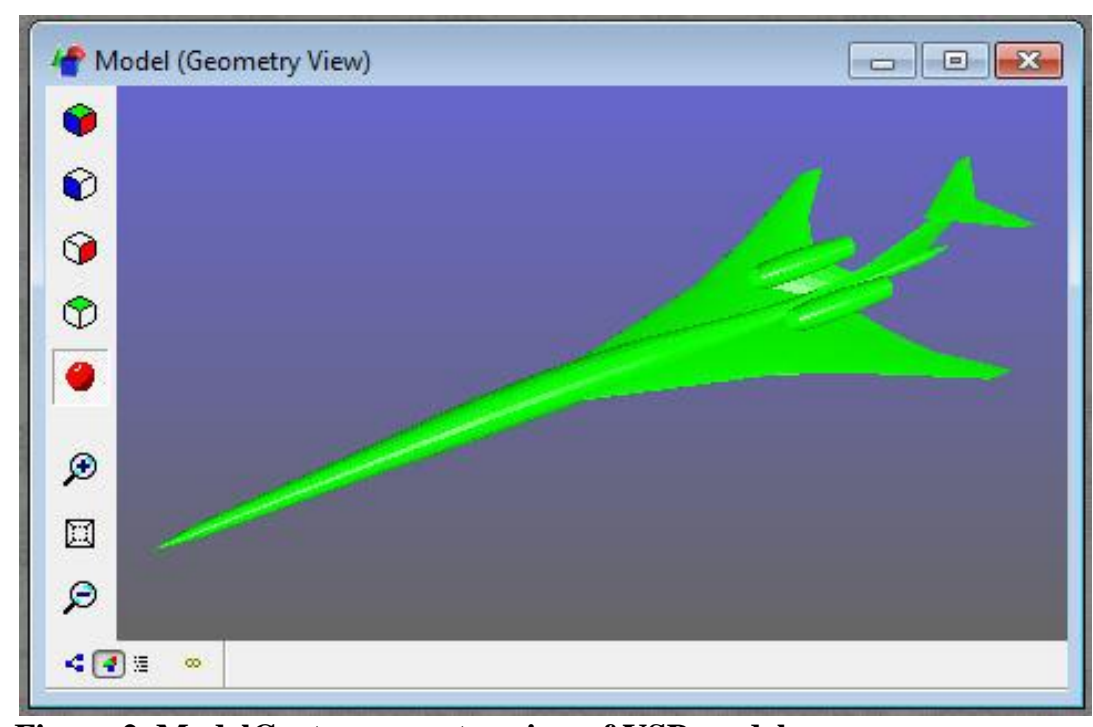

Figure 2. ModelCenter geometry view of VSP model. also automatically export its parametric geometry as a closed triangulation mesh suitable for Cart3D CFD analysis.

Initially, a baseline geometry can be laid out using the standalone VSP graphical user interface. A ModelCenter Plugin has been developed to load a VSP parametric geometry into ModelCenter and to expose the desired geometric parameters of interest. Any future modification of the exposed geometry variables can quickly be modified within the VSP plug-in. This provides a very flexible means of changing design variables for shape optimization within ModelCenter. Additionally, the geometry can be visually examined during the ModelCenter execution process to monitor the impact of geometric design variable changes to the aircraft shape. This is particularly helpful during optimization or parametric variation. Figure 2 shows a ModelCenter Geometry View window in which the current VSP geometry has been selected for display as a shaded solid. Other options include selections for displaying the original and intermediate geometries as wireframes or shaded solids.

In addition to the basic outer mold line (OML) geometry, additional components allow the user to set up geometric constraints related to the vehicle, such as sizes and locations of landing gear, control surfaces, fuel tanks, passenger cabin, and various ground clearance angles. This information then becomes available to constrain the OML optimization or to regenerate non OML geometry information necessary for the analysis process.

\section{Wing Design and Lift Matching Assembly}

Once the propulsion system has been developed and the geometry is modeled, the process includes options for doing a wing camber surface design ${ }^{40}$ for the given planform to minimize the drag for a fixed $\mathrm{C}_{\mathrm{L}}$. This camber surface design process can be skipped if airfoil section parameters from the VSP geometry are included in the overall system level optimization. In addition, the user can select to skip any wing camber optimization if desired. A lift matching process is then executed to determine the angle of attack for the required $C_{L}$ and the given tail deflection. The camber surface design and lift matching module is currently composed of modified linear theory tools. A future improvement to this module will include the addition of a process for CFD based camber designs. This automated CFD analysis has already been implemented in a ModelCenter process but has not been included in the current build for wing camber design.

4

American Institute of Aeronautics and Astronautics 


\section{A A $_{\mathrm{e}}$ Based Low-Boom Design Assembly}

The low-boom design module capabilities have been developed to provide both automated and user interactive operation, for both $\mathrm{A}_{\mathrm{e}}$ target development and $\mathrm{A}_{\mathrm{e}}$ target matching. There are currently two options to generate target equivalent areas. The Hybrid code ${ }^{41}$ uses the George-Seebass-Darden boom minimization theory to generate target $\mathrm{A}_{\mathrm{e}}$ distributions for low-boom design. In addition, a parametric $\mathrm{A}_{\mathrm{e}}$ target generation tool was developed to generate $\mathrm{A}_{\mathrm{e}}$ targets for low-boom design that allow tradeoffs between $A_{e}$ volume requirements for a configuration and the PLdB level of the ground signature. ${ }^{42}$ Additionally, the process contains a method for shaping fuselage and fuselage like components to match the $A_{e}$ of the configuration to the target $\mathrm{A}_{\mathrm{e}} \cdot{ }^{43}$ Future development plans include the addition of methods for off body pressure target generation and matching as an additional approach for low-boom design. Figure 3 provides a high level view of the $A_{e}$ based low-boom design assembly.

Equivalent area calculations are available at low, mixed, and high-fidelity levels. The supersonic modified linear aerodynamics computer program, LTSTAR ${ }^{44}$ is used to generate the low-fidelity $A_{e}$ due to lift and HWAVE, a streamlined and modified version of the Harris far-field wave drag program ${ }^{45}$, is used for volume $\mathrm{A}_{\mathrm{e}}$. Modifications to the original Harris far-field wave drag code have removed some of its restrictive

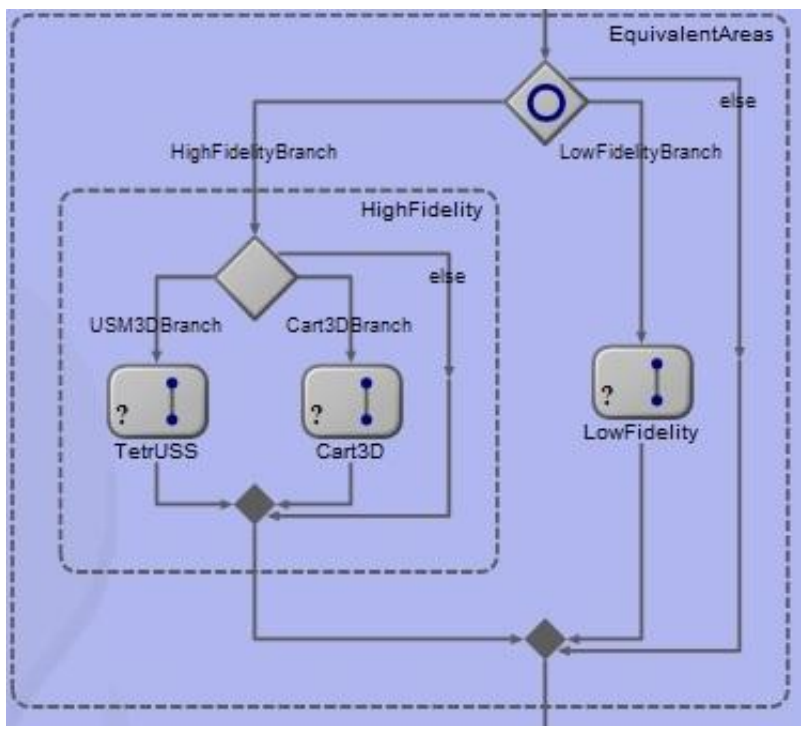

Figure 3. $A_{e}$ based low-boom design assembly. requirements for geometry definition. CFD based equivalent areas can also be calculated. Two high-fidelity CFD codes were selected based on speed and accuracy. Cart3D is a high-fidelity inviscid analysis package that uses adaptively refined Cartesian meshes for conceptual and preliminary aerodynamic design. Cart3D runs relatively fast and has less restrictive requirements on the input geometry definition than other CFD codes. USM $3 \mathrm{D}^{46}$ is an Euler/Navier-Stokes solver for unstructured, tetrahedral meshes. USM3D is slower, but can be used with SSGRID ${ }^{47}$ to shear and stretch the VGRID generated grid to enable computing off-body pressure distributions for propagation to the ground. The processes for both CFD codes are completely automated and include options for selecting processors, using restart files, automated interactive generation of many plots for visualizing grids and flow field properties to examine the results if desired. The low-boom design methodology using the low and mixed-fidelity capabilities are documented in detail in Ref. 14.

\section{Aerodynamic Analysis Assembly}

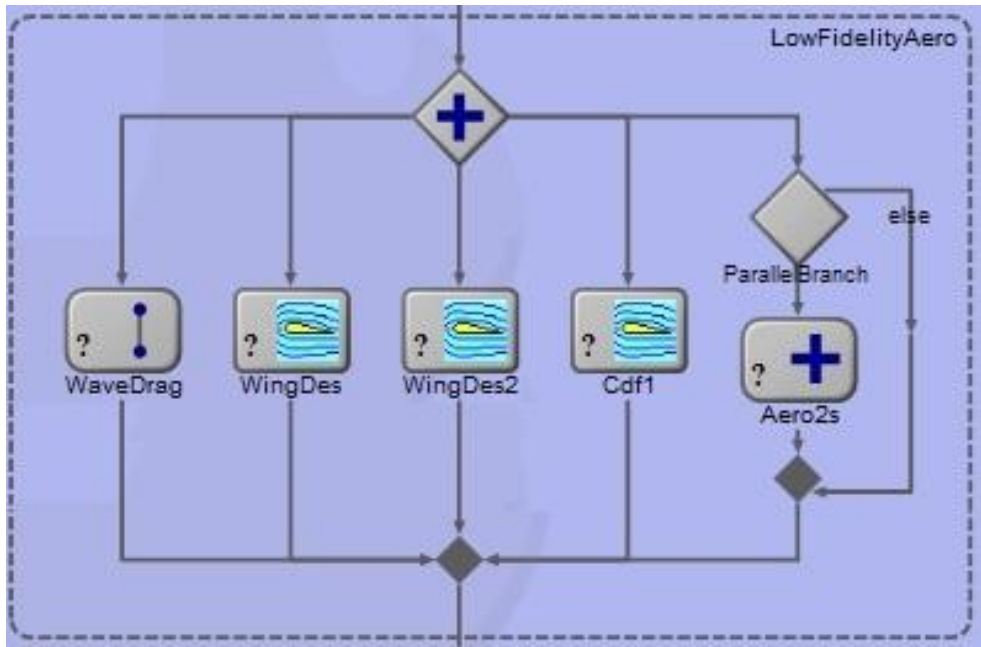

Figure 4. Aerodynamic analysis assembly.
Currently, aerodynamic analyses are divided into two categories, low-fidelity and high-fidelity. At this time, low-fidelity analysis methods are used during optimization and the high-fidelity results can be used as a final verification. The low-fidelity aerodynamics data is generated using a collection of tools $\mathrm{s}^{40,45,48}$ with runtimes varying from fractions of a second to several seconds depending on the tier. The low-fidelity analysis module is shown in Figure 4. The high-fidelity CFD tools and processes are generally the same as those used in the high-fidelity $A_{e}$ analysis process. Future enhancements to this module are expected to include automated methods for using high-fidelity results to correct low-fidelity results. 


\section{Sonic Boom Analysis Assembly}

There are multiple options for generating sonic boom ground signatures within the processs as depicted in the high level view of the sonic boom analysis assembly in Fig. 5. The low-fidelity sonic boom analysis uses the $A_{e}$ due to lift from LTSTAR and the $A_{e}$ due to volume from HWAVE which is then propagated to the ground with $\mathrm{ARAP}^{49}$ or $\mathrm{sBOOM}^{50}$. sBOOM can take a dp/p distribution, an Ffunction or $A_{e}$ as input and can also be used to generate off-track sonic boom signatures for $d p / p$ inputs. The mediumfidelity option (shown in the right branch of Fig. 5) uses the total $A_{e}$ from CFD propagated using sBOOM. The highest fidelity option uses the mid field pressure distribution from Cart3D or USM3D and propagates the signature using either $\mathrm{PCBOOM}^{51}$ or $\mathrm{sBOOM}$. The integrated analysis process uses the resulting

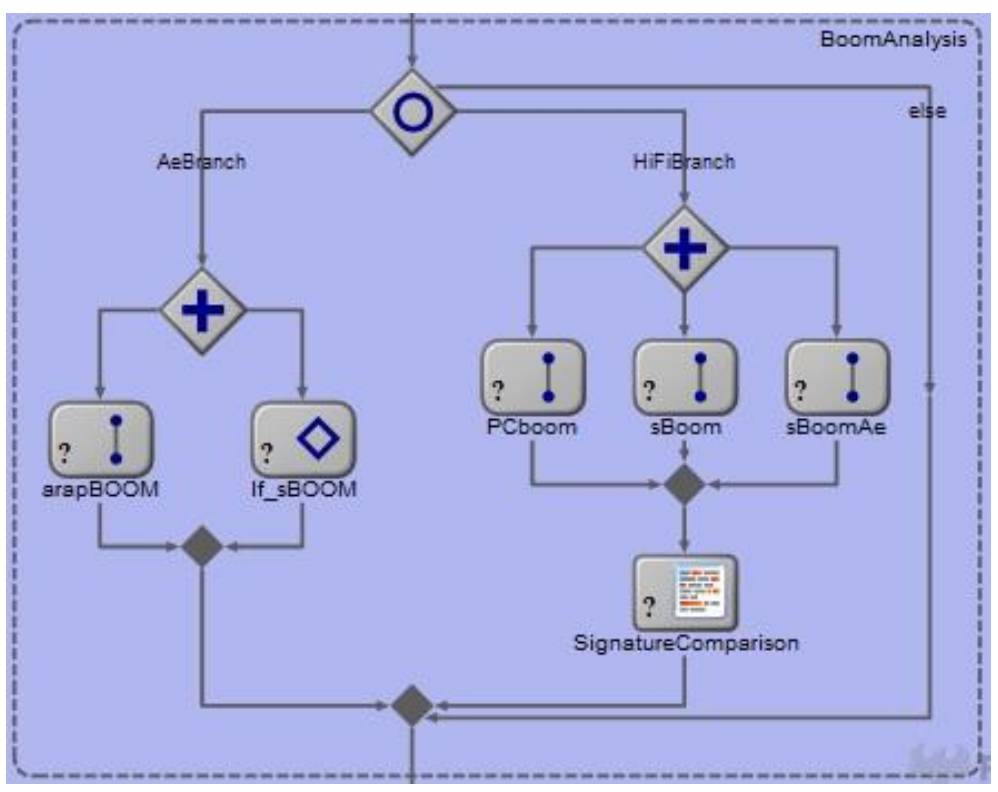

Figure 5. Sonic boom analysis assembly. signature from each code to calculate a perceived loudness based on the method of Stevens Mark VII ${ }^{52}$ and the subjective loudness tests of Shepherd and Sullivan ${ }^{53}$.

\section{Performance Analysis Assembly}

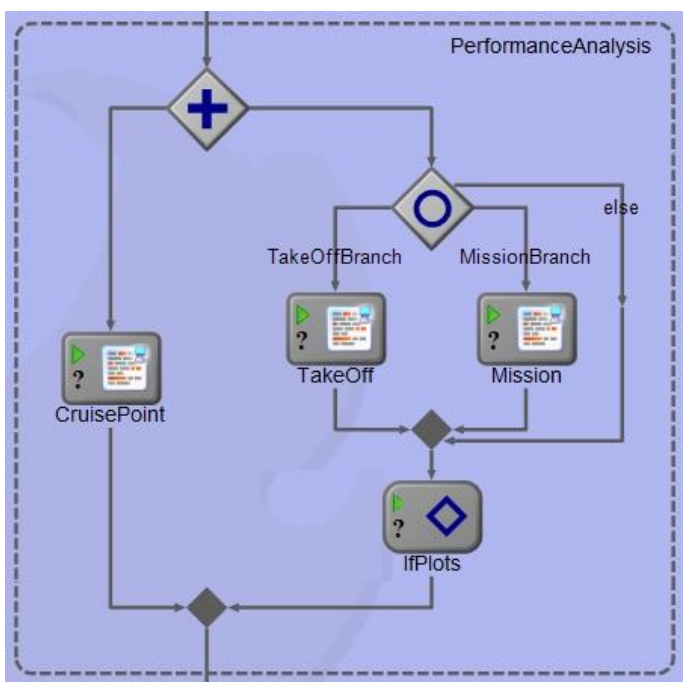

Figure 6. Performance analysis assembly.

The performance analysis assembly is shown in Fig. 6. The overall aircraft performance is also divided into three tiers, based on execution time. The simplest measure of aircraft performance is the Breguet range, requiring just the aircraft weight, cruise $\mathrm{L} / \mathrm{D}$, and cruise SFC as inputs. A tier I analysis is significantly faster than a tier III and is useful when designing primarily for a low cruise drag shape balanced against a lowboom shape; however, those results can be very misleading if the shape changes are large. As such, the tier I approach should not be used during optimization, especially when large changes in the design variables are allowed. For supersonic transport aircraft, there are typically three design points that must be taken into account in the overall vehicle shaping; takeoff, transonic pinch point and supersonic cruise. Tier II adds detailed takeoff and landing ${ }^{54}$ constraints to the tier I design. This provides a way to balance the necessary takeoff field length performance with cruise performance. Tier II adds constraints which balances the high and low speed design results for critical items such as planform geometry and/or the propulsion system.

Because all of the low-fidelity aerodynamics and $A_{e}$ analysis codes can execute in parallel, tier II execution time is not much longer than just running tier I. The third tier adds the full mission performance analysis, ${ }^{54}$ which requires complete aerodynamic performance data throughout the flight envelope and a complete engine deck for the propulsion system. During design space exploration, this data can be easily generated with low-fidelity tools for each design, but it does significantly slow down the optimization process. The avarage run time for each tier, without any design, is shown in Table 1 . These times can vary significantly depending on computer, computer load

Table 1. Execution time comparison for various tiers of analysis.
\begin{tabular}{|llll|}
\hline & Cruise & Takeoff & Envelope \\
\hline No Propulsion Analysis & $44(37) \mathrm{sec}$ & $55 \mathrm{sec}$ & $63 \mathrm{sec}$ \\
\hline With Propulsion Analysis & $68 \mathrm{sec}$ & $88 \mathrm{sec}$ & $151 \mathrm{sec}$ \\
\hline
\end{tabular}


avarage, and network traffic. Also, these times show that the amount of time required for low-boom and low-drag optimizations requiring thousands of iterations with a large number of design variables can be substantial, even at low-fidelity. Some of the boom propagation codes can be skipped in tier I (time shown in parenthesis in Table 1) because they can have a relatively large impact on execution time.

\section{Community Noise Analysis Assembly}

Community noise analysis is performed using the Aircraft Noise Prediction Program (ANOPP, level 26 version 2). ${ }^{35,55}$ ANOPP can predict the total aircraft noise from engine component and airframe noise sources. Figure 7 shows the noise source module from the community noise assembly where potential noise sources are selected for analysis. These include fan inlet, fan exit, turbine, core, jet, and airframe; and can include engine noise shielding by the wing. The geometry data object is passed to the ANOPP input interface and combined with the detailed engine geometry from WATE++ to create an ANOPP input file which includes the location of the wing relative to each of the

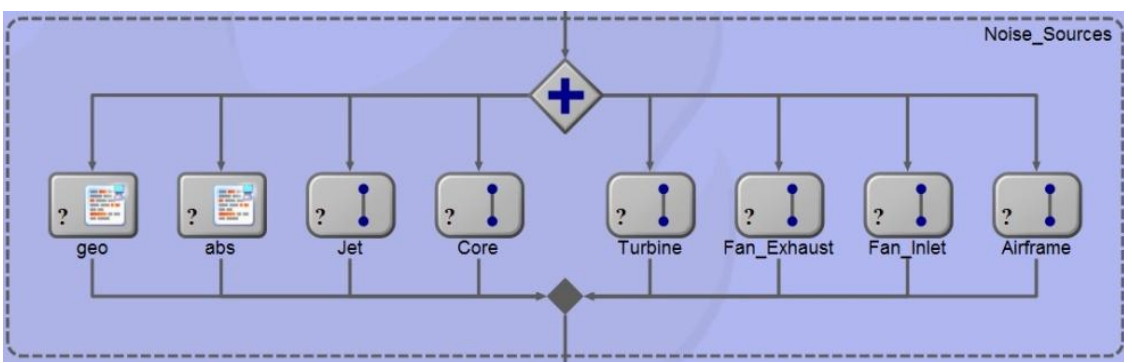

Figure 7. Noise source assembly. engine noise sources. Takeoff, climb out, approach and landing performance data and the flight trajectory generated during the tier II and III performance analyses feed the ANOPP analysis process. Executing ANOPP adds 40 to 160 seconds to run and as such, during optimization, when ANOPP is executed, the model includes "do not execute" options for all noise sources except jet noise.

\section{Using the Process for Optimization}

There is no one optimization process that has been found to work well for overall design of efficient and environmentally friendly supersonic transports. Low-boom design, in particular, requires many design variables to adequately and accurately explore the design space. This large number of required design variables limits the choice of optimizers when derivatives are not available. The choices and numbers of these design variables, their ranges,

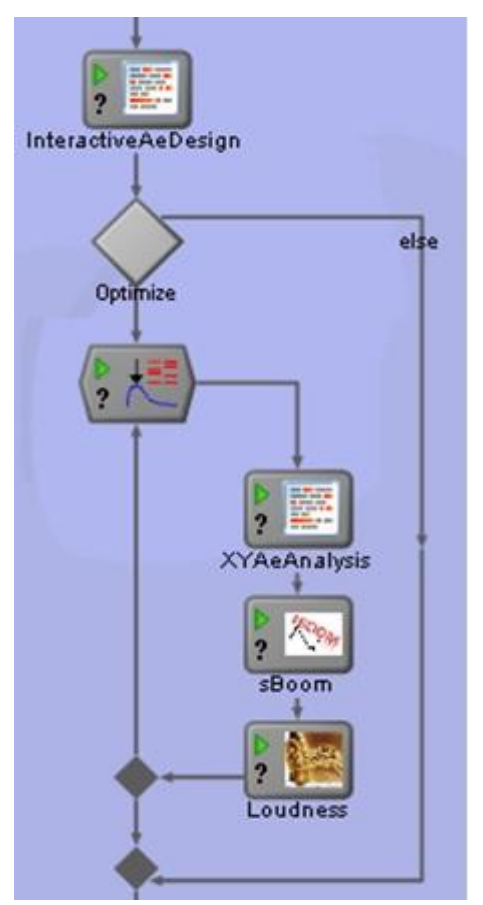

Figure 8. Embedded Darwin optimizer for low-boom design. and their effects on all the disciplines are expansive. For example, main landing gear length affects where the gear can be located, the design of primary wing and fuselage structure, the fuel tank capacity and locations, and ground clearance during takeoff and landing, etc. For low-boom and low-drag design, the design variables, with the exception of the engine parameters, are essentially all geometric in nature. In its current state, the model does not account for all interactions between all potential design variables and all the disciplines. Furthermore, these interactions might not be well quantified thereby limiting the levels of fidelity which can be applied to the modeling process. Without a basic low-fidelity structural analysis, an expansive low-fidelity optimization can and will lead to unrealistic designs.

A variety of optimization formulations can be used with the current integrated analysis and design process. Any optimizer can be used as a driver for the entire model or be embedded as an integral part of the model. Two examples will be used to demonstrate the extent of the current capabilities using the Boeing Design Explorer ${ }^{56}$ optimization tool available within ModelCenter. Design Explorer uses an orthogonal array to populate the design space and runs the analyses at each point in the array. Next, it builds a surrogate model, optimizes on that surrogate, and then runs an analysis on the result, continually refining the surrogate model until an optimum solution is found. The DOT ${ }^{57}$ (Design Optimization Tools) optimization tool within ModelCenter is a generalpurpose gradient-based optimization software library that can be used to solve a wide variety of optimization problems. Current experience indicates that the DOT optimization tool works better than the others when there are many design variables (without gradients), provided that the objective and constraints are

American Institute of Aeronautics and Astronautics 
relatively well behaved. A third example will be used to demonstrate its use. An additional optimization tool available within the process is the Darwin Genetic algorithm. Darwin was found to be too time consuming for use with any tier of analyses when applied to the overall process. It can, however, be useful for smaller sub-optimization problems within the current process. For example, it can be used to generate potential volume constrained low-boom $\mathrm{A}_{\mathrm{e}}$ targets using sonic boom loudness as the objective. Figure 8 shows the Darwin Genetic optimizer embedded in the model in an "If" block after the interactive $A_{e}$ design component. It can optionally be used to attempt to further reduce the loudness level achieved interactively (human in the loop), by perturbing the $\mathrm{x}, \mathrm{y}$ coordinates of the original $\mathrm{A}_{\mathrm{e}}$ spline curve to minimize the loudness of the ground signature generated by sBOOM. An additional option available to the user is Phoenix Integration's PHXSolver which allows users to integrate their own optimization algorithms in ModelCenter using a common user interface. This new ModelCenter feature is expected to provide future flexibility for studying new optimization strategies and methods within this process as they are identified or developed.

\section{A. Propulsion System Design Using Design Explorer}

In the first example of low-fidelity optimization, Design Explorer was used to optimize the propulsion system design. The objective was to maximize range of a baseline concept, subject to constraints on takeoff jet velocity $\left(\mathrm{V}_{\text {jet }}\right)$, maximum compressor exit temperature $\left(\mathrm{T}_{3}\right)$, takeoff field length (FAROFF), and maximum combustor exit temperature $\left(\mathrm{T}_{4}\right)$. The six design variables used in the example were the overall pressure ratio (OPR), fan pressure ratio (FPR), extraction ratio (EXTR), throttle ratio (TTR), design $\mathrm{T}_{4}$, and takeoff thrust. The initial and final design variable values are shown in Table 2 . As would be expected, the jet velocity and $\mathrm{T}_{4, \max }$ are at their respective upper limits of 1600 $\mathrm{ft} / \mathrm{s}$ and $4200{ }^{\circ} \mathrm{R}$. Figure 9 was generated from the response surface created during the optimization using the RSM toolkit supplied in the Data Explorer. It shows range contours and the contours for the two active constraints, $V_{\text {jet }}$ and $\mathrm{T}_{4, \max }$ versus two of the design variables, $\mathrm{T}_{4}$ and OPR. It should be noted that the initial range is suboptimal due to the initial thrust being too high. With the optimal thrust of approximately $27,000 \mathrm{lbs}$ the range is $2804 \mathrm{nmi}$. The fact that the reduction in $V_{\text {jet }}$ actually increases the range indicates that the baseline propulsion system had been sub-optimal for this configuration.

Table 2. Propulsion system optimization results.

\begin{tabular}{|lll|}
\hline Variable & Initial & Result \\
\hline OPR & 39.21 & 32.00 \\
\hline FPR & 2.500 & 2.343 \\
\hline EXTR & 0.9000 & 0.9919 \\
\hline TTR & 1.1000 & 1.1519 \\
\hline $\mathrm{T}_{4},{ }^{\circ} \mathrm{R}$ & 4000 & 3998 \\
\hline Thrust, $\mathrm{lb}^{\circ}$ & 25,000 & 23,860 \\
\hline $\mathrm{V}_{\text {jet }}, \mathrm{ft} / \mathrm{s}$ & 1726 & 1602 \\
\hline $\mathrm{T}_{3}{ }^{\circ} \mathrm{R}$ & 797.7 & 812.1 \\
\hline $\mathrm{T}_{4, \mathrm{max}}{ }^{\circ} \mathrm{R}$ & 4115 & 4204 \\
\hline FAROFF, $\mathrm{ft}$ & 4197 & 4782 \\
\hline Range, $\mathrm{nmi}$ & 2754 & 2868 \\
\hline
\end{tabular}

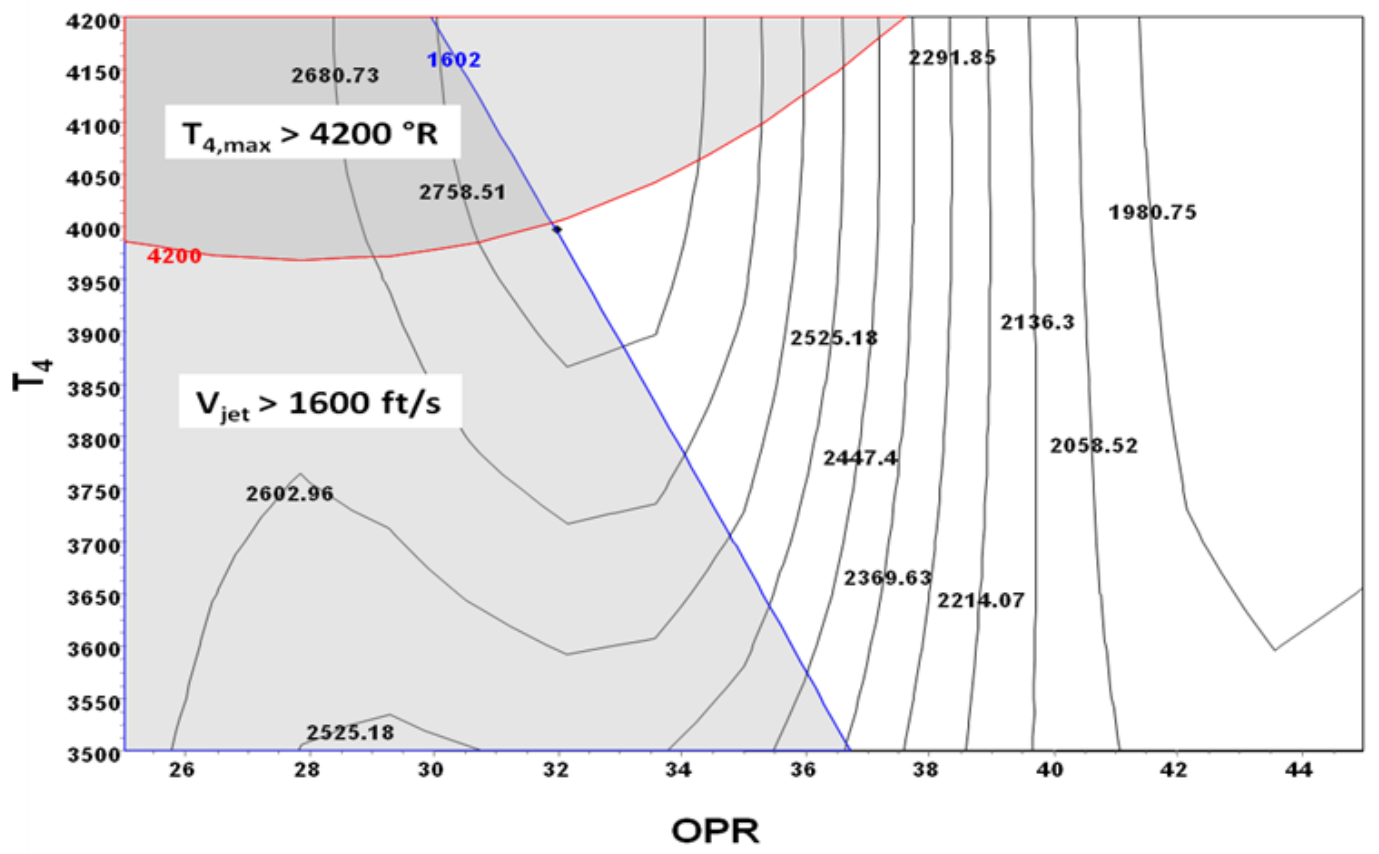

Figure 9. Propulsion system optimization response surface results. 


\section{B. Propulsion System and Planform Design Using Design Explorer}

In the next example, the same optimizer was applied to the planform and three primary propulsion system design variables (Thrust, FPR, and OPR), and the objective was to maximize the range. The wing is modeled in VSP as a multi-section wing with four sections. The fifteen design variables used in this example were the leading edge sweep for each section, the root/tip chords, the span for the three outboard sections, and the three propulsion system variables. The starting point for the propulsion system parameters was the result from the previous example. The results for the propulsion system are listed in Table 3 and the initial (black) and final (red) planforms are shown in Fig. 10. Although the range improvement is significant, this result shows that the current optimization process is exploiting weaknesses in the low-fidelity weights analysis.

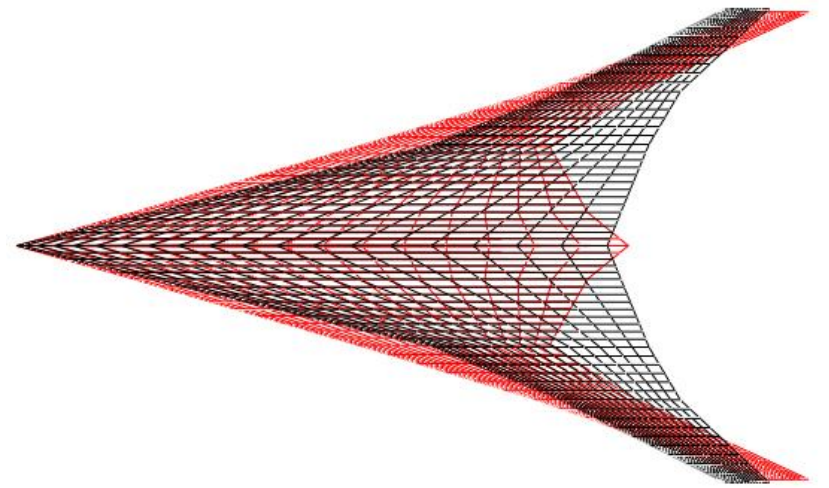

Table 3. Propulsion system results with planform optimization.

\begin{tabular}{|lll|}
\hline Variable & Initial & Result \\
\hline OPR & 32.00 & 32.29 \\
\hline FPR & 2.342 & 2.340 \\
\hline Thrust & 23,800 & 23,800 \\
\hline$V_{\text {jet }}, \mathrm{ft} / \mathrm{sec}$ & 1602 & 1600 \\
\hline FAROFF, ft & 4782 & 3720 \\
\hline Range, $\mathrm{nmi}$ & 2868 & 3396 \\
\hline
\end{tabular}

Figure 10. Initial (black) and final (red) planform shapes.

\section{Planform Design using the DOT Optimizer}

In the final example, the gradient based DOT optimizer was applied to the planform and engine thrust (by selecting the option to "scale NPSS" to scale the weight and nacelle geometry from the first example) to maximize the range. The same initial wing planform design from the previous example is used here. In this case, the eleven design variables were the four leading edge sweeps for each section, the span and tip chords for the three out board sections, and the thrust. The takeoff field length is limited to $4600 \mathrm{ft}$ (close to the baseline) and the approach velocity is limited to $130 \mathrm{kts}$. For this example geometry constraints have been added to keep the leading and edge sweep from increasing from inboard to outboard and to maintain a trailing edge sweep that is greater than zero. The

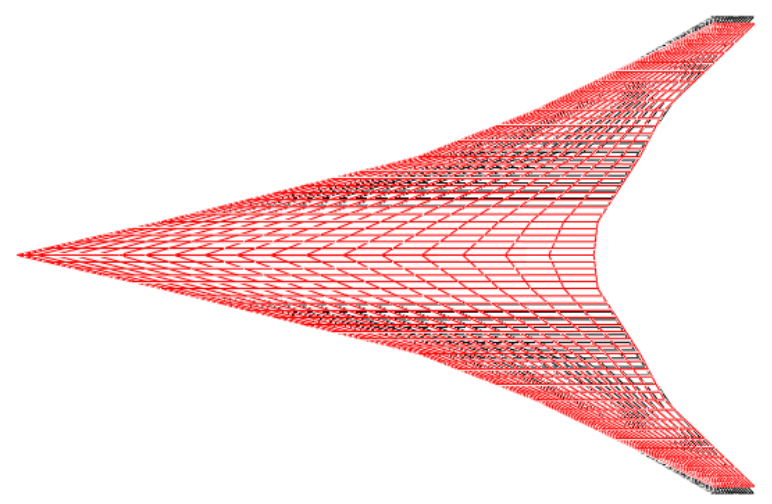

Figure 11. Initial (black) and final planform shapes. results are summarized in Table 4. Here the active constraint is the approach velocity. This resulted in a better planform design (see Fig. 11), at least from a structural standpoint, but has a lower range than the previous example.

Table 4. Result summary for planform optimization.

\begin{tabular}{|lll|}
\hline Variable & Initial & Result \\
\hline Thrust, lb & 26,434 & 27,747 \\
\hline $\mathrm{V}_{\text {app }}$ kts & 131.6 & 129.9 \\
\hline FAROFF, ft & 4782 & 4454 \\
\hline Range, nmi & 2763 & 2982 \\
\hline
\end{tabular}

\section{Summary of Optimization in the Process}

The choice of optimizer is highly dependent on the extent of the design space and the robustness of the analysis tools in the model. All of the optimizers currently available in the process can deal with failed cases, but some seem to deal with them better than others. In the propulsion system example, the Design Explorer was used because of its ability to deal with failed cases, the low number of design variables, and the relatively high cost for each function evaluation. In fact, as many as two-thirds of the cases in the first orthogonal array failed. In the last 120 iterations, there were only twelve failed cases. Furthermore, the extent of the design space is highly dependent on the choice of 
optimizer. Sampling methods, like Design Explorer, are generally inadequate if the design space is large (greater than about 30 design variables) and gradient methods do not work well when the function evaluations are noisy. The interactions between the design variables and the various disciplines, especially when the design space is large, can be difficult to fully grasp a priori. This can result in some degree of trial and error. As the development of the integrated design and analysis tool proceeds, analysis tool robustness can be improved, constraints can be activated, and new constraints can be developed in order to avoid "bad" results and increase the optimizers' chances of achieving a good result.

\section{Conclusions \& Future Work}

A conceptual level integrated design and analysis process for application to the development of efficient and environmentally acceptable supersonic aircraft concepts has been developed. The process provides a robust, flexible and user friendly capability to supersonic concept designers and has proven to be an invaluable tool within the Systems Analysis Branch at NASA Langley for studying supersonic aircraft. The capability allows the user to quickly assess a variety of problem formulations and optimization algorithms while maximizing design space exploration. It also provides a seamless capability to switch between low and high-fidelity methods, for a number of disciplines, within one integrated system. The current capability has evolved over a number of years, and has been instrumental in the success of a number of NASA studies, and has been a driver for the continued development of other new computational tools. The introduction of process flow, conditional linking, and data objects has made the model easier for development and maintenance, and has simplified user interactions.

The capability described herein remains under continual development and improvement. Many new features under development have already been mentioned in previous sections. As indicated in the examples shown, there are still shortcomings related to accurate structural weight impacts on the thin, highly swept wings that optimizers tend to drive the shape toward during optimization for supersonic concepts. To address this shortcoming, a "lowfidelity" NASTRAN based structural analysis capability is currently being implemented in the model. One of the key difficulties in integrating higher fidelity capabilities, like structures and CFD, is that they often lack the degree of robustness required for an automated MDAO process and these difficulties are challenges that are yet to be overcome. We have made significant advancements in the aspects of automation of geometry for grid generation and for CFD, but still have work to do in the area of higher fidelity structural analyses. As challenging as these advancements may be, they are necessary for successful supersonic aircraft design.

\section{References}

1 Choi, S., Alonso, J., and Kroo. M., "Two-Level Multi-Fidelity Design Optimization Studies for Supersonic Jets," Journal of Aircraft, Vol. 46, No. 3, pp 776-812, May-June 2009.

2 Choi, S., Alonso, J., Kroo, I., and Wintzer, M., "Multifidelity Design Optimization of Low-Boom Supersonic Jets,” Journal of Aircraft, Vol. 45, No. 1, pp 106-118, January-February 2008.

3 Kazuhisa, C., Y. Makino, and Takatoya, T., "Multidisciplinary Design Exploration of Wing Shape for Silent Supersonic Technology Demonstrator," AIAA Paper 2007-4167, June 2007.

4 Alonso, J., LeGresley, P. and Pereyra, V., "Aircraft design optimization," Journal of Mathematics and Computers in Simulation, Volume 79 Issue 6, February 2009.

5 Alonso, J., Kroo, I. and Jameson, V., “Advanced Algorithms for Design and Optimization of Quiet Supersonic Platforms," AIAA Paper 2002-0144, January 2002.

6 von Reith, D., "Experience and Potential of Multidisciplinary Optimization Tools on Supersonic Aircraft," AIAA Paper 1997-5515, Oct. 1997.

7 Giunta, A., Balabanov, V., Haim, D., Grossman, B., Mason, W., Watson, L., and Haftka, R., "Multidisciplinary Optimization of a Supersonic Transport Using Design of Experiments Theory and Response Surface Modeling,” Virginia Polytechnic Institute \& State University Blacksburg, VA, USA, 1997.

8 Wintzer, M., Sturdza, P., and Kroo, I., "Conceptual Design of Conventional and Oblique Wing Configurations for Small Supersonic Aircraft," 44th AIAA Aerospace Sciences Meeting and Exhibit; Reno, NV; USA; 9-12 January 2006.

9 Neittaanmäki, P., Rossi, T., Korotov, S., Oñate, E., Périaux, J., Knörzer, D., "Multidisciplinary Optimisation of Supersonic Transport Aircraft Wing Planform," ONERA - Applied Aerodynamics Department, July 2004.

10 Geiselhart, K. A., A Technique for Integrating Engine Cycle and Aircraft Configuration Optimization. NASA CR-191602, February 1994. 
11 Chattopadhyay, A. and Pagaldipti, N., "A Multidisciplinary Optimization using Semi-Analytical Sensitivity Analysis Procedure and Multilevel Decomposition," Computers Math. Appl., Vol. 29, No. 7, pp. 55-66, 1995.

12 de Saint Martin, P., Stoufflet, B.,. Deremaux, Y., Négrier, J., "Design of a Small Supersonic Transport Aircraft with High Environmental Constraints," ICAS Paper 2008-8.0.3, August-September 2004.

13 Kim, Yushin, Lee, D., Kim, Yonghyup, and Yee, K., "Multidisciplinary Design Optimization of Supersonic Fighter Wing Using Response Surface Methodology” AIAA Paper 2002-5408, September 2002.

14 Li, W., Shields, E., and Geiselhart, K., "A Mixed-Fidelity Approach for Design of Low-Boom Supersonic Aircraft," AIAA Paper 2010-0845, January 2010.

15 Li, W., Shields, E., and Le, D., "Interactive Inverse Design Optimization of Fuselage Shape for Low-Boom Supersonic Concepts," AIAA Paper 2008-136, January 2008.

16 Yoshikazu, M., "Low sonic-boom design of a silent supersonic technology demonstrator: Development of CAPAS and its application," $4^{\text {th }}$ SST-CFD Workshop, pages 697-705, 2007.

17 Choi, S., Alonso, J., and Chung. S., "Design of a Low-Boom Supersonic Business Jet Using Evolutionary Algorithms and an Adaptive Algorithms and an Adaptive," AIAA Paper 2004-1758, April 2004.

18 Argrow, B., Maute, K., Farhat, C., Nikbay, M., "F-function lobe balancing for sonic boom minimization," Computational Fluid Dynamics Journal, Vol. 17, No. 4, pp. 221-234, 2009.

19 Chung, H. and Alonso, J., "Design of a Low-Boom Supersonic Business Jet Using Cokriging Approximation Models," AIAA Paper 2002-4344, April 2002.

20 Lei, Z., and Makino, Y., "CFD-Based Aerodynamic Shape Optimization for Japanese Experimental Supersonic Transport," ICAS Paper 2004-4.3.3, August-September 2004.

21 Vazquez, M., Dervieux, A., and Koobus, B., "Aerodynamical and Sonic Boom Optimization of a Supersonic Aircraft," INRIA Report 4520, July 2002.

22 Le, D., "A Wing Design Methodology for Low-Boom Low-Drag Supersonic Business Jet," Publication Number: AAT 3364894, January 2010.

23 Le, D., "Design Modifications to Achieve Low-Boom and Low-Drag Supersonic Conceptual Designs," VSGC Paper 2006-2007, 2007, URL: http://www.vsgc.odu.edu/src/SRC07/SRC07papers/Daniel\%20Le\%20\%20VSGC\%20PAPER\%2020062007_LE.pdf [cited 6 December 2010].

24 Sato, K., Kumano, T., Yonezawa, M., Yamashita, H., Jeong, S., and Obayashi, S., "Low-Boom and Low-Drag Optimization of the Twin Engine Version of Silent Supersonic Business Jet," Journal of Fluid Science and Technology, Vol. 3, No. 4, pp 576-585, 2008.

25 Vazquez, M., Dervieux, A., and Koobus, B., "Multilevel Optimization of a Supersonic Aircraft," Finite Elements in Analysis and Design, Volume 40, Issue 15, pp 2101-2124, September 2004.

26 Chung, H. and Alonso, J., "Multiobjective Optimization Using Approximation Model-Based Genetic Algorithms," AIAA Paper 2004-4325, April 2004.

27 Y. Makino, Aoyama, T., and Iwamiya, T., Watanuki, T., and Kubota, H. "Numerical Optimization of Fuselage Geometry to Modify Sonic-Boom Signature,” Journal of Aircraft, Vol. 36, No. 4, pp 668-674, July-August 1999.

28 Kubota, H., "Sonic Boom Alleviation for Next-Generation Supersonic Transport," Manuscript received February 4, 2007, URL: http://internetjournals.net/journals/tar/2007/July/Paper\%2005.pdf [cited 6 December 2010].

29 Rallabhandi, S., "Sonic Boom Minimization through Vehicle Shape Optimization and Probabalistic Acoustic Propagation," Dissertation, Georgia Institute of Technology, April 2005, URL:

http://smartech.gatech.edu/handle/1853/6937 [cited 6 December 2010].

30 Maute, K., Farhat, C., Argrow, B., and Nikbay, M., "Sonic Boom Mitigation Via Shape Optimization Using an Adjoint Method and Application to a Supersonic Fighter Aircraft," University of Colorado, Boulder, January 2006, URL: http://www.stanford.edu/group/frg/publications/recent/re_sboom3.pdf [cited 6 December 2010].

31 Phoenix Integration, Inc., ModelCenter, Design Integration Software (Version 9.0), 1715 Pratt Drive, Suite 2000, Blacksburg, VA 24060, www.phoenix-int.com [cited 6 December 2010].

32 Ozoroski, L. P., Geiselhart, K. A., Padula, S. L., Li, W., Olson, E. D., Campbell, R. L., et.al.; "Initial Multidisciplinary Design and Analysis Framework," NASA/TM-2010- 216711, June 2010.

33 Lytle, J., Follen, G., Naiman, C., Evans, A., Veres, J., Owen, K., and Lopez, I., "Numerical Propulsion System Simulation (NPSS) 1999 Industry Review," NASA/TM-2000-209795, August 2000.

34 Onat, E. and Klees, G. W.: "A Method to Estimate Weight and Dimensions of Large and Small Gas Turbine Engines,” NASA CR-159481, January 1979. 
35 Zorumski, W. E., “Aircraft Noise Prediction Program Theoretical Manual,” NASA TM 83199, National Aeronautics and Space Administration, 1982.

36 Hahn, Andrew S., "Vehicle Sketch Pad: A Parametric Geometry Modeler for Conceptual Aircraft Design," AIAA 2010-657, January 2010.

37 Walatka, P., Buning, P., Pierse, L., Elson, P., "PLOT3D User's Manual," NASA Technical Memorandum 101067, March 1990.

38 Cart3D, "What is Cart3D?" Version 1.4, NASA Ames Research Center, Dec. 2008, URL: http://people.nas.nasa.gov/ aftosmis/cart3d/ [cited 6 December 2010].

39 VGRID, "VGRID Unstructured Grid Generator," NASA Langley Research Center, August 8, 2003, URL: http://tetruss.larc.nasa.gov/usm3d_v52/usm3d 52 man.html [cited 6 December 2010].

40 Carlson, H. W.; Chu, J.; Ozoroski, L. P.; and McCullers, L. A.: "Guide to AERO2S and WINGDES Computer Codes for Prediction and Minimization of Drag Due to Lift," NASA TP-3637, November 1997.

41 Mack, R. and Haglund, G.: "A Practical Low-Boom Overpressure Signature Based on Minimum Sonic Boom Theory,” High-Speed Research: Sonic Boom Workshop, NASA CP-3173, Vol. 2, 1992, pp. 15-29.

$42 \mathrm{Li}, \mathrm{W}$. and Shields, E., "Generation of Parametric Equivalent Area Targets for Design of Low-Boom Supersonic Concepts,” AIAA Paper, AIAA No. Pending, Jan. 2011.

43 Li, W., Shields, E., and Le, D. "Interactive Inverse Design Optimization of Fuselage Shape for Low-Boom Supersonic Concepts,” AIAA Paper 2008-136, January 2008.

44 Carlson, H. W.; Mack, R. J. "Estimation of Wing Nonlinear Aerodynamic Characteristics at Supersonic Speeds," NASA TP 1718, November 1980.

45 Harris, Roy V., Jr., "An Analysis and Correlation of Aircraft. Wave Drag,” NASA TM X-947, 1964.

46 USM3D, "USM3D Users Manual," Version 6.0, NASA Langley Research Center, August 28, 2006, URL: http://tetruss.larc.nasa.gov/usm3d_v52/usm3d_52_man.html [cited 6 December 2010].

47 Campbell, L., Carter, M., and Deere, K., and Waithe, K., "Efficient Unstructured Grid Adaptation Methods for Sonic Boom Prediction," AIAA Paper 2008-7327, August 2008.

48 Sommer, S. and Short, B., "Free-Flight Measurements of Turbulent-Boundary-Layer Skin Friction in the Presence of Severe Aerodynamic Heating at Mach Numbers from 2.8 to 7.0.," NACA TN-3391, 1955.

49 Hayes, W. D. and Haefeli, R. C., "The ARAP Sonic Boom Program," Sonic Boom Workshop, Ed. I. A. Schwartz, NASA SP-180, 1968, pp. 151-158.

50 Rallabhandi, Sriram K., "Advanced Sonic Boom Prediction Using Augmented Burger's Equation," AIAA Paper, AIAA No. Pending, Jan. 2011.

51 Plotkin, K. and Page, J., "Extention of PCBoom to Over-the-top Booms, Ellipsoidal Earth, and Full 3-D Ray Tracing." AIAA-2007-3677, June 2007.

52 Cleveland, R. O., "Propagation of Sonic Booms through a Real, Stratified Atmosphere," Ph.D. dissertation, The University of Texas at Austin, 1995.

53 Shepherd, K. and Sullivan, B., "Loudness Calculation Procedure Applied to Shaped Sonic Booms," NASA TP3134, 1991.

54 McCullers, A., "Aircraft Configuration Optimization Including Optimized Flight Profiles. Multidisciplinary Analysis and Optimization - Part I," NASA CP-2327, 1984. (The Flight Optimization System: Release 8.12, Revised June, 2010 Available with public distribution of software).

55 Gillian, R. E.: “Aircraft Noise Prediction Program User's Manual,” NASA TM-84486, January 1982.

56 Booker, Andrew J, Meckesheimer, Martin, and Toring, Tony, "Reliability Based Design Optimization Using Design Explorer" Optimization and Engineering, 5, 179-205, 2004.

57 Vanderplaats Research \& Development, Inc., DOT - Design Optimization Tools (Version 5.0), 1767 S. 8th Street, Suite 210, Colorado Springs, CO 80906, www.vrand.com [cited 6 December 2010]. 